\title{
The Sclera, M. S. De La Maza, J. Tauber, C. S. Foster 2013, ISBN: 978-1-4419-6501-1 Springer
}

\author{
M. Stanford
}

Received: 18 June 2014 / Accepted: 21 June 2014 / Published online: 12 July 2014

(C) Springer-Verlag Berlin Heidelberg 2014

This is the second edition of the popular textbook on the sclera. As before, the text covers the anatomy, physiology and pathology of this organ in great and accurate detail. Diseases of the sclera are covered in an expert manner and useful advice is given on the treatment of these.

An additional chapter covering the main systemic features of the rheumatological and infectious causes is helpful. Whilst the quality of the colour photographs is good, the black and white pictures suffer a loss of detail which could perhaps be redressed in subsequent editions.

Some of the newer drugs available for the treatment of associated systemic diseases (eg biologic agents) could be given more room, as these are likely to influence therapy in the coming years.

It would have been useful to mention the role of subconjunctival steroids in diffuse and nodular disease. However, apart from these minor caveats, the authors should be congratulated on the new edition. 